\title{
Crisaborole and its potential role in treating atopic dermatitis: overview of early clinical studies
}

\begin{abstract}
Atopic dermatitis (AD), a chronic, relapsing, inflammatory skin disease that is characterized by intense pruritus and eczematous lesions with up to $90 \%$ of patients presenting with mild to moderate disease. Current topical treatments for AD have not changed in over 15 years and are associated with safety concerns. In AD, overactivity of phosphodiesterase 4 (PDE4), leads to inflammation and disease exacerbation. Crisaborole Topical Ointment, $2 \%$, is a novel, nonsteroidal, topical anti-inflammatory PDE4 inhibitor currently being investigated for the treatment of mild to moderate AD. Preliminary studies in children and adults demonstrated favorable efficacy and safety profiles. Crisaborole may represent an anti-inflammatory option that safely minimizes the symptoms and severity of $A D$ and that can be used for both acute and long-term management.
\end{abstract}

First draft submitted: 2 February 2016; Accepted for publication: 6 April 2016; Published online: 10 June 2016

Keywords: atopic dermatitis • Crisaborole Topical Ointment, $2 \% \bullet$ cytokine $\bullet$ inflammation $\bullet$ pharmacokinetics $\bullet$ phosphodiesterase 4 inhibitor $\bullet$ pruritus $\bullet$ quality of life $\bullet$ topical calcineurin inhibitor $\bullet$ topical corticosteroid

Atopic dermatitis (AD) or eczema, one of the most common inflammatory skin diseases, is characterized by chronic and relapsing episodes of intense pruritus, an impaired epidermal barrier and eczematous lesions [1-3]. It occurs most frequently in children, but also affects adults [4]. In industrialized countries, the incidence of AD has increased by two- to threefold since $1950[5,6]$. The prevalence of $\mathrm{AD}$ is 15 to $30 \%$ in children and 2 to $10 \%$ in adults [2]. Approximately $85 \%$ of patients experience symptoms by the time they are 5 years old $[5,7] .20 \%$ of individuals who develop AD before the age of 2 years continue to experience manifestations of the disease, with a waxing/ waning pattern [7], and these manifestations often persist into their second decade of life [8].

AD-associated pruritus imposes psychological, social and quality of life (QoL) burdens on patients and their families [5,9-12]. $\mathrm{AD}$ also represents a significant financial burden [5,12]. The estimated annual cost of $\mathrm{AD}$, even without its comorbidities, approaches US $\$ 3.8$ billion [11]. Mean total direct medical costs in the USA from 1998 to 2005 were significantly higher for patients with AD than for controls without AD (US $\$ 349$ vs US $\$ 261$ per patient per month, respectively; $\mathrm{p}<0.001)$ [13].

Disease management focuses on alleviating symptoms and preventing flares [14]. AD has been called the 'itch that rashes' [15], and chronic, localized or general pruritus is the hallmark of the condition [3,16-18]. Up to $90 \%$ of patients present with mild to moderate $\mathrm{AD}[19,20]$, and disease severity is correlated with the intensity of pruritus [21]. In a study of 89 pediatric patients, $45 \%$ of those with mild AD and $75 \%$ of those with moderate AD reported daily itch, 20\% and 19\% experienced weekly itch and the remaining patients experience itch at an interval greater than 7 days [21].
LT Zane, ${ }^{*}$, S Chanda', K Jarnagin', DB Nelson', L Spelman² \& LF Stein Gold ${ }^{3}$

${ }^{1}$ Anacor Pharmaceuticals, Inc., 1020 East Meadow Circle, Palo Alto, CA, USA

${ }^{2}$ Veracity Clinical Research, Queensland, Australia

${ }^{3}$ Henry Ford Health System, Detroit, MI, USA

*Author for correspondence:

Tel.: +1 6505437536

Izane@anacor.com
Future :

Medicine part of 


\section{Etiology}

The root cause of AD involves several processes, but both genetic and environmental factors contribute to its development [5]. The strongest known genetic link with $\mathrm{AD}$ is related to mutations of the gene encoding filaggrin $[3,18,22]$, a skin matrix protein that promotes keratin aggregation, a part of the completion of the squamous layer [23]. These mutations are thought to be associated with skin barrier impairment, a key feature of the disease $[5,6,18,22,24]$. Researchers have also identified several other genes that are involved with the skin barrier response and immune dysregulation associated with $\mathrm{AD}[24,25]$. While genetic mutations are associated with $\mathrm{AD}$, there are many $\mathrm{AD}$ patients without genetic alterations, indicating that these mutations explain only part of the disease pathology [26].

AD-related skin barrier disruption results in increased water loss [25], leading to dry skin. These changes cause increased susceptibility to allergic sensitization, infection and microbial colonization $[6,24,27,28]$. Skin barrier disruption is correlated with disease severity [24,29] and associated with an increased risk of the 'atopic march' [5]. Patients affected by this phenomenon experience a progression of atopic manifestations, beginning with $\mathrm{AD}$ and progressing to allergic rhinitis or asthma in later life [5].

Inflammation is associated with elevated phosphodiesterase (PDE) activity [12,30]. Increased levels of PDE4, an intracellular enzyme found in inflammatory cells such as macrophages, $\mathrm{T}$ cells, monocytes and neutrophils [31], are seen in patients with active AD and in those with inactive allergic rhinitis [30]. PDE4 is involved in controlling the production of inflammatory cytokines, such as interleukin-4 (IL-4), IL-5, IL-10, IL-13 and prostaglandin E2, through the degradation of cyclic adenosine monophosphate (cAMP) [12,31-36]. Inhibition of PDE4 increases intracellular cAMP, which then activates protein kinase A (PKA) [37,38]. Activation of PKA leads to the phosphorylation of target proteins, some of which are involved in the control of cytokine production, such as cAMP-response-element-binding protein (CREB) [39,40], NF-kB [41,42], NFAT [43], Rap1 [44] and Csk [45]. These changes in cytokine production result in an imbalance of T-cell activity, characterized by a reduction in regulatory $\mathrm{T}$ cells and an increase in T-helper (Th)-2 cells [2,22]. Thus, the involvement of PDE 4 in the pathology of $\mathrm{AD}$ makes it a potential therapeutic target for disrupting the inflammatory cycle characteristic of this disease.

\section{Burden of atopic dermatitis}

Because of the associated pruritus, QoL can be substantially impaired for patients with $\mathrm{AD}$ and the parents of children with AD. Although there is no specific diagnostic test for $\mathrm{AD}$, the intensity of pruritus is a major criterion $[46,47]$ for categorizing disease severity and assessing clinical outcomes $[4,21,48,49]$.

In individuals with $\mathrm{AD}$, pruritus can lead to longterm psychological problems, including anxiety, depression and suicidal ideation [50-54]. The prevalence of mental health issues is higher in patients with $\mathrm{AD}$ than in the general population, and pruritus has a detrimental effect on comfort levels and sleep [52,55-57].

Clinical depression is common in individuals with AD. In an observational cross-sectional study of adults recruited from dermatologic outpatient clinics in 13 European countries, $10.1 \%$ of patients with $\mathrm{AD}$ and $4.3 \%$ of controls had depression as assessed by the Hospital Anxiety and Depression Scale ( $p<0.001$ for comparison) [57]. The adjusted odds ratio for depression in participants with $\mathrm{AD}$ was 3.27 (95\% confidence interval: 1.61-6.62) [57]. In addition, multiple studies in a variety of countries have reported suicidal ideation in $>15 \%$ of patients with $\mathrm{AD}[56,58,59]$. A strong correlation has been found between patient-rated dermatological disease severity, psychologic burden and suicidal ideation $[56,60]$.

Children with pruritus may exhibit increased daytime behavioral changes that are likely secondary to pruritus-related sleep disorders [9,61]. These changes can lead to impaired school performance and an increased risk of developing emotional and social problems during adolescence $[9,61]$. Attention deficit hyperactivity disorder is 1.5-times more prevalent in children with $\mathrm{AD}$ than in those without $\mathrm{AD}$, and this relationship appears to be causal [55].

Given the many negative consequences of ADrelated pruritus, achieving improved disease control is essential for breaking the itch-scratch cycle, preventing chronicity and scarring and improving QoL $[9,62]$. Moreover, better disease control might mitigate the increased risk of mental health problems $[51,52,55,56,58,60]$, prevent recurrent bacterial and viral skin infections [55] and slow the atopic march [55,63]. Improved control could also make it possible to limit the continuous use of and side effects associated with mid- to high-potency topical corticosteroids (TCS) that are commonly prescribed to treat $\mathrm{AD}[4]$.

\section{Current topical treatment paradigms for atopic dermatitis}

Nonpharmacologic treatments

Nonpharmacologic treatments for AD include physical and psychosocial interventions. Physical interventions that appear to have the greatest therapeutic potential are wearing silk or silver-impregnated clothing, dilute bleach baths, wet-wrap therapy, aggressive moisturization, vitamin D supplementation and phototherapy. 
Other approaches include allergen avoidance, climate and temperature changes, dietary modification and probiotic consumption $[4,64,65]$. The value of these approaches is limited by a lack of research on their optimal frequency and the consequences of combining them with TCS therapy. Psychosocial interventions, including hypnosis and education, as well as biofeedback and participation in support groups, have shown promise, but further investigation is required to understand their efficacy in treating patients with $\operatorname{AD}[4,64,65]$. Nonpharmacologic treatments must be used consistently if they are to be effective, but optimal regimens for patients with the various types of $\mathrm{AD}$ have not yet been established.

\section{Pharmacologic treatments}

According to guidelines developed by the American Academy of Dermatology and the American Academy of Allergy, Asthma, and Immunology, major considerations in treating $\mathrm{AD}$ include using agents that are safe for younger patients and that are both effective and safe for treating $\mathrm{AD}$ signs and symptoms in sensitive skin areas and larger body surface areas (BSAs) over an extended period of time [4]. Pharmacologic topical treatments that are commonly prescribed for $\mathrm{AD}$ have changed very little over the past 15 years, consisting primarily of topical corticosteroids (TCS) and topical calcineurin inhibitors (TCI) [66]. TCS have been used to treat AD since the early 1950 s $[4,67]$, and two TCI were introduced as therapies for $\mathrm{AD}$ in 2000 and $2001[4,68]$.

\section{Topical corticosteroids}

TCS reduce inflammation and pruritus $[4,9,16,20,49,62]$ by acting on various immune cells to disrupt antigen processing and presentation and by suppressing the release of proinflammatory cytokines $[4,69,70]$. They are frequently prescribed to treat the acute and chronic signs of $\mathrm{AD}$ in adults and children [4,49]. The type of lesion, age of the patient and area of skin requiring treatment are important considerations in selecting among the many different TCS preparations and doses that are currently available [64].

The effectiveness of TCS for reducing AD-related inflammation and pruritus is well established $[4,7,20]$, but their use is limited by local and systemic adverse effects [4]. These concerns are particularly relevant in children, who have a greater surface area-to-body weight ratio, and thus the potential for more substantial exposure [4]. Local, potency-dependent side effects of short-term TCS treatment include burning and itching [71], secondary infection and skin atrophy [20]. For acute flares, TCS are often used daily for up to several weeks, and proactive use (once to twice weekly) is recommended for chronic relapsing areas [4]. Potential adverse effects of long-term treatment include striae, folliculitis, acne-like eruptions, focal hypertrichosis, allergic contact dermatitis, glaucoma, papilloedema and telangiectasia $[4,66,69]$. Long-term TCS treatment is associated with an increase in the risk of tachyphylaxis to TCS, and hypothalamic-pituitary-adrenal axis suppression, Cushing syndrome, growth retardation, glucose intolerance, peptic ulcer disease, neuropsychiatric manifestations and other adverse effects $[4,66,69]$.

Application of high-potency TCS is restricted in areas such as the thin-skinned eyelids, periocular area, face, axillae and genitals due to an increased risk of adverse events $[19,20,64,67]$. The structure of skin in these areas, characterized by a thin epidermis, extensive vascularization or many epidermal appendages and nerve endings, causes it to be more absorbent $[20,69]$. Therefore, TCS should not be used under occlusion in these areas $[4,20,49,67]$, and patients prescribed TCS should be closely monitored $[20,72,73]$ and educated about proper uses [16].

\section{Topical calcineurin inhibitors}

TCI are immunosuppressants that act by inhibiting T-cell and mast cell activation, thereby reducing the production of proinflammatory cytokines and mediators of the inflammatory reaction in $\mathrm{AD}[4,14]$. Tacrolimus $(0.03$ and $0.1 \%)$ and pimecrolimus (1\%) are the TCI drugs that are currently approved to treat moderate to severe or mild to moderate $\mathrm{AD}$, respectively $[4,14,16]$.

The most commonly observed adverse effects associated with TCI treatment are application site burning and stinging $[4,14,16]$. Additionally, a boxed warning was added to the pimecrolimus and tacrolimus labels in 2006 due to concerns about a potential link between TCI use and increased lymphoma risk [14]. Recent epidemiologic evidence suggests that the incidence of lymphoma is no greater in TCI-treated patients than in the general population [14]. Thus, no causal relationship between TCI use and malignancies or lymphoma as a result of immune suppression has been confirmed [74-76]. The US FDA has concluded that the possibility of such an association may still exist, and the boxed warning for lymphoma risk remains in place [14]. Patient education about the potential side effects of TCI therapy is important for optimizing adherence to the treatment regimen [19].

\section{Development of Crisaborole Topical Ointment, $2 \%$, for atopic dermatitis} Clinical pharmacology \& mechanism of action Crisaborole is a small-molecule, boron-based, selective PDE4 inhibitor that modulates multiple immune and inflammatory pathways (Figure 1) [77-79]. It has a low molecular weight, of $251 \mathrm{Da}$ [77] that provides 
<smiles>N#Cc1ccc(Oc2ccc3c(c2)COB3O)cc1</smiles>

Figure 1. Chemical structure of crisaborole [77].

good skin penetration. The presence of boron in this benzoxaborole structure confers the ability to inhibit PDE4 by acting as a mimic of the phosphate of cAMP [80]. Its unique geometry enables it to target and inhibit PDE4, which degrades cAMP [80]. By inhibiting PDE4, crisaborole increases intracellular cAMP levels [35]. Increased cAMP suppresses the activity of the NF- $\kappa \mathrm{B}$ [42] and other pathways responsible for inflammatory cytokine production [31,36] including CREB [39,40], NFAT [36], Rap1 [44] and Csk [45] leading to the suppression of cytokine synthesis (Figure 2) [80]. In vitro analysis demonstrated crisaborole inhibits the production of a selection of Th1 and Th2 proinflammatory cytokines, including IFN- $\gamma$, TNF- $\alpha$, IL-2,
IL-5 and IL-10 [80]. Thus, crisaborole has the potential to control inflammation [78-80], and future studies may elucidate the ability of crisaborole to inhibit other inflammatory mediators.

Crisaborole is suitable for topical formulation because of its physicochemical properties and low molecular weight, which allow it to penetrate the epidermis and dermis to reach the site of inflammation. Once it reaches the systemic circulation, crisaborole is rapidly metabolized to inactive metabolites, resulting in limited systemic exposure [81].

\section{Phase I and II data: pharmacokinetics, efficacy} \& safety

One Phase Ib and three Phase II clinical trials were performed to analyze the pharmacokinetics, efficacy and safety of crisaborole in children and adults (Table 1) [82-85]. Global disease severity was analyzed by the Investigator's Static Global Assessment (ISGA). The protocols for these studies excluded use of crisaborole on the scalp, due to the anticipated cosmetic

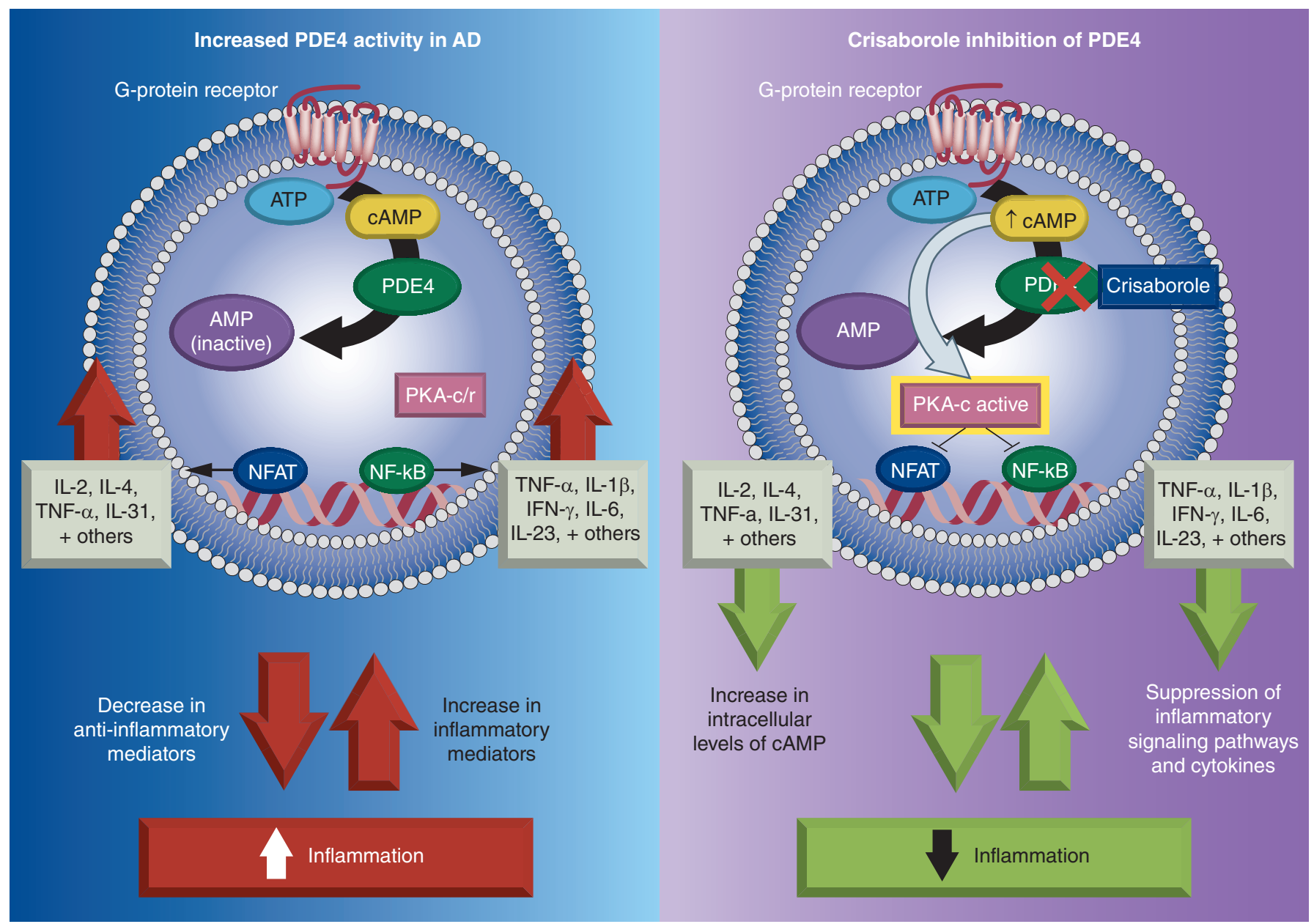

Figure 2. Mechanism of action of crisaborole. AD: Atopic dermatitis; ATP: Adenosine triphosphate; CAMP: cyclic adenosine monophosphate; IFN- $\gamma$ : Interferon gamma; IL: Interleukin; NFAT: Nuclear factor of activated T cells; NF- $\kappa B$ : Nuclear factor $\kappa B$; PDE4: Phosphodiesterase 4; PKA-c/r: CAMP-dependent protein kinase catalytic subunits $\mathrm{c}$ and $\mathrm{r}$; TNF- $\alpha$ : Tumor necrosis factor alpha. 
Table 1. Study design and outcomes for Phase I and Phase II clinical trials.

\begin{tabular}{|c|c|c|c|c|c|c|}
\hline \multirow{2}{*}{$\begin{array}{l}\text { Study } \\
\text { number }\end{array}$} & \multirow{2}{*}{$\begin{array}{l}\text { Study } \\
\text { description }\end{array}$} & \multirow[t]{2}{*}{ Primary end point } & \multirow{2}{*}{$\begin{array}{l}\text { Key secondary end } \\
\text { points }\end{array}$} & \multirow{2}{*}{$\begin{array}{l}\text { Cohort age } \\
\text { range, years }\end{array}$} & \multicolumn{2}{|c|}{ AD assessment } \\
\hline & & & & & Efficacy at day 29 & $\begin{array}{l}\text { Pruritus (pooled } \\
\text { analysis) }\end{array}$ \\
\hline 203 & $\begin{array}{l}\text { Phase Ila, } \\
\text { open-label, } \\
\text { safety, } \\
\text { tolerability } \\
\text { and PK } \\
\text { study, } \mathrm{n}=23 \text {, } \\
\text { whole body } \\
\text { assessment }\end{array}$ & $\begin{array}{l}\text { PK plasma profiles } \\
\text { of crisaborole } \\
\text { and its oxidative } \\
\text { metabolites } \\
\text { AN7602 and } \\
\text { AN8323 on days } 1 \\
\text { and } 8\end{array}$ & $\begin{array}{l}\text { Treatment success at } \\
\text { days } 8,15,22 \text { and } 29 ; \\
\text { ISGA score of clear ( } 0) \\
\text { or almost clear }(1) \text { and } \\
\geq 2 \text {-grade improvement } \\
\text { from baseline at days } 8, \\
15,22 \text { and } 29\end{array}$ & $12-17$ & $\begin{array}{l}34.8 \% \text { Crisaborole } \\
\text { Topical Ointment, } \\
2 \% \text {-treated } \\
\text { patients achieved } \\
\text { treatment success }{ }^{\ddagger}\end{array}$ & \\
\hline 202 & $\begin{array}{l}\text { Phase lla, } \\
\text { vehicle- } \\
\text { controlled, } \\
\text { proof-of- } \\
\text { concept } \\
\text { study, } \mathrm{n}=25, \\
\text { target lesion } \\
\text { assessment }\end{array}$ & $\begin{array}{l}\text { Change in ADSI } \\
\text { score from baseline } \\
\text { at day } 28\end{array}$ & $\begin{array}{l}\text { Change from baseline } \\
\text { in ADSI score at days } 14 \\
\text { and } 42\end{array}$ & $18-75$ & $\begin{array}{l}68.0 \% \text { vs } \\
20.0 \% \text { achieved } \\
\text { treatment success, } \\
\text { (Crisaborole Topical } \\
\text { Ointment, } 2 \% \\
\text { vs vehicle) }\end{array}$ & $\begin{array}{l}\text { Significant } \\
\text { reduction in } \\
\text { mean pruritus } \\
\text { severity scores } \\
\text { by day } 15^{*}\end{array}$ \\
\hline 204 & $\begin{array}{l}\text { Phase II, } \\
\text { bi-lateral, } \\
\text { dose-finding } \\
\text { study, } n=86, \\
\text { target lesion } \\
\text { assessment }\end{array}$ & $\begin{array}{l}\text { Change in ADSI } \\
\text { score from baseline } \\
\text { at days } 8,15,22 \\
\text { and } 29\end{array}$ & $\begin{array}{l}\text { Proportion of target } \\
\text { lesions achieving total or } \\
\text { partial clearance (ADSI } \\
\leq 2 \text { ) }\end{array}$ & $12-17$ & $\begin{array}{l}\text { Crisaborole } \\
\text { Topical Ointment, } \\
2 \% \text { twice daily } \\
\text { achieved greatest } \\
\text { improvement from } \\
\text { baseline ADSI score }\end{array}$ & \\
\hline
\end{tabular}

incompatibility of ointment and long hair, as well as precluding application near venous access areas. The use of emollients, TCS and TCI was restricted during treatment with crisaborole.

\section{Pharmacokinetics}

Studies 102 and 203 analyzed the pharmacokinetic properties of Crisaborole Topical Ointment, 2\% (primary end points). In Study 102 (a maximal use systemic exposure study), the mean observed maximum plasma concentration after maximal dosing $\left(\mathrm{C}_{\max }\right)$ with crisaborole was $111 \mathrm{ng} / \mathrm{ml}$, indicating low systemic exposure; the mean time to reach $\mathrm{C}_{\max }\left(\mathrm{T}_{\max }\right)$ was 3 h on days 1 and 8 [82].

In Study 203 (NCT01652885), the pharmacokinetic profile also reflected rapid absorption of cri- saborole, with a median $\mathrm{T}_{\max }$ of $2.37 \mathrm{~h}$ on day 1 and $2.17 \mathrm{~h}$ on day 8 (Table 2) [84]. Crisaborole mean $\mathrm{C}_{\max }$ and $t_{1 / 2}$ values in plasma were $105 \mathrm{ng} / \mathrm{ml}$ and $7.17 \mathrm{~h}$ on day 1 , and $94.6 \mathrm{ng} / \mathrm{ml}$ and $11.9 \mathrm{~h}$ on day 8 , respectively. After absorption into the systemic circulation, crisaborole was quickly metabolized to AN7602 and AN8323, the two identified inactive oxidative metabolites in plasma. Both of these metabolites are inactive as PDE4 inhibitors [86]. The extent of systemic exposure to crisaborole increased as the amount of applied crisaborole increased. Steady state of crisaborole and its metabolites was achieved within 4 to 6 days [84].

\section{Safety}

Pooled safety analysis across all 4 studies included patients as young as 2 years of age, and patients 
Table 2. Mean (SD) plasma pharmacokinetic parameters for crisaborole in Study 102 and 203.

\begin{tabular}{|c|c|c|c|c|c|}
\hline Analyte & $\begin{array}{l}\text { Dose } \\
\text { day }\end{array}$ & $\mathrm{C}_{\max } \mathrm{ng} / \mathrm{ml}$ & $\begin{array}{l}\mathrm{T}_{\max }(\mathrm{h}), \text { median } \\
\text { (range) }\end{array}$ & $\begin{array}{l}\operatorname{AUC}_{(0-12)^{\prime}} \\
\mathrm{ng} \cdot \mathrm{h} / \mathrm{ml}\end{array}$ & $t_{1 / 2}, h$ \\
\hline \multicolumn{6}{|l|}{ Study 102 (Age range: $2-17$ ) } \\
\hline Crisaborole & Day 8 & $127(196)^{\theta}$ & $3.00(3-24)^{\theta}$ & $949(1240)^{\dagger}$ & $\mathrm{n} / \mathrm{a}$ \\
\hline AN7602 & Day 1 & $37.8(35)$ & $3.00(3-12)$ & $247(224)^{\dagger}$ & $\mathrm{n} / \mathrm{a}$ \\
\hline AN8323 & Day 1 & $2270(2640)$ & $12.0(3-24)$ & $16,800(16,900)^{\dagger}$ & $\mathrm{n} / \mathrm{a}$ \\
\hline [5-(4-cyanophenoxy)-2-hydroxybenzoic acid] & Day 8 & $6150(4790)^{\theta}$ & $3.00(0-24)^{\theta}$ & $63,400(49,000)^{\dagger}$ & $\mathrm{n} / \mathrm{a}$ \\
\hline \multicolumn{6}{|l|}{ Study $203^{\ddagger}$ (Age range: $12-17$ ) } \\
\hline \multirow[t]{2}{*}{ Crisaborole } & Day 1 & $105(160)$ & $2.37(1.00-24.0)$ & $448(527)$ & $7.17^{\S}(2.30)$ \\
\hline & Day 8 & $94.6^{\text {ก }}(189)$ & 2.17 (1.00-7.93) & $462^{\uparrow}(506)$ & $11.9 \#(8.28)$ \\
\hline [5-(4-cyanophenoxy)-2-hydroxybenzoic acid] & Day 8 & 1850 ๆ (1830) & $6.00^{\text {ๆ }}(0.00-25.1)$ & 18,200 ๆ $(18,100)$ & $33.5^{f}(10.1)$ \\
\hline \multicolumn{6}{|c|}{ 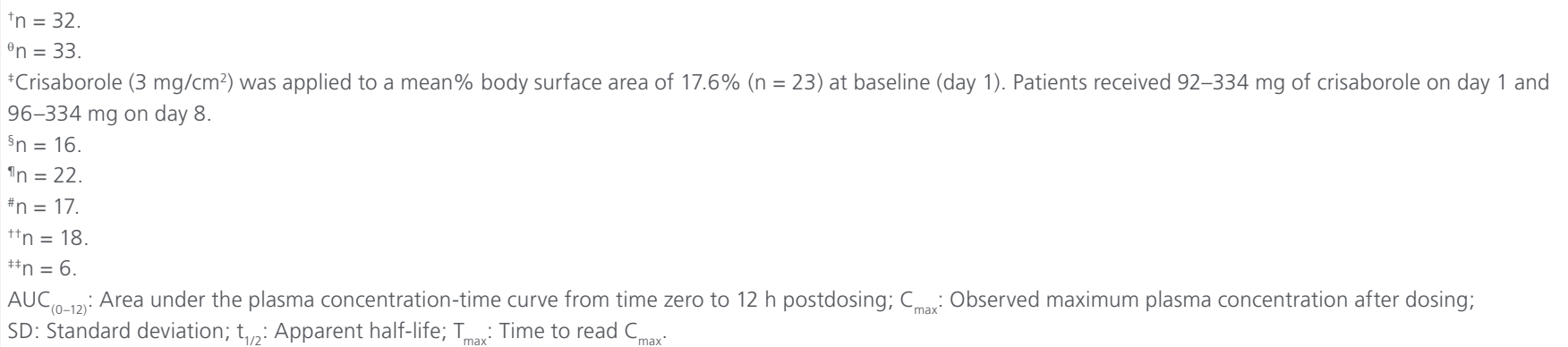 } \\
\hline
\end{tabular}

exposed to maximal dosing conditions. Across all four studies 61 of 168 participants (36.3\%) reported one or more treatment-emergent adverse events (TEAEs) (Table 3). Of the 131 TEAEs reported, 95 (72.5\%) were considered mild, 33 (25.2\%) were considered moderate and $3(2.3 \%)$ were considered severe. None of the severe TEAEs were considered serious or related to treatment. Only 2 of $168(1.1 \%)$ of patients discontinued treatment due to a treatment-related AE (application site dermatitis, application site pain) $[82,84]$. The most commonly reported treatmentrelated AEs were application site pain, dermatitis and pruritus [82-85].

\section{Efficacy}

Study 102 was a Phase Ib multicenter, open-label, maximal-use systemic exposure study evaluating Crisaborole Topical Ointment, 2\%, applied twice daily for 28 days in patients aged 2-18 years with AD involving $\geq 25 \%$ of treatable BSA [82]. At baseline, the overall patient population had a mean $\%$ treatable BSA of $48.7 \%$ (range: 27-92\%). At day 29, 16 of 34 patients $(47.1 \%)$ achieved treatment success, defined as ISGA score of 0 (Clear) or 1 (Almost Clear) with $\geq 2$-grade improvement from baseline (secondary outcome). Mean severity scores for the 5 AD signs and symptoms from baseline to day 29 (secondary outcome) are shown in Figure 3. Throughout the study, crisaborole treatment resulted in a marked reduction in the severity of all signs and symptoms, indicating that crisaborole provides early and sustained relief of the signs and symptoms of AD. The mean \% treatable BSA (secondary outcome) decreased throughout the study. The mean (SD) percentage change from baseline in the percentage of affected BSA at day 29 was $-77.7 \%(22.1 \%)$ [82].

Study 202 (NCT01301508) was a Phase II, proof-of-concept, multicenter, randomized, doubleblind, vehicle-controlled, 6-week study conducted in adults with mild to moderate AD [83]. 25 adults were randomized to apply Crisaborole Topical Ointment, $2 \%$, to one target lesion and ointment vehicle to a second target lesion. At day 28, 17 patients $(68.0 \%)$ experienced a greater improvement in the Atopic Dermatitis Severity Index (ADSI) score for the crisaborole-treated lesion compared with 
Table 3. Summary of treatment-emergent adverse events reported in Phase I/II studies of crisaborole to date.

\begin{tabular}{|c|c|c|c|c|c|c|}
\hline Variable & $\begin{array}{l}\text { Study } 202 \\
(n=25)\end{array}$ & $\begin{array}{l}\text { Study } 203 \\
(n=23)\end{array}$ & $\begin{array}{l}\text { Study } 204 \\
\text { QD }(n=44)\end{array}$ & $\begin{array}{l}\text { Study } 204 \\
\text { BID }(n=42)\end{array}$ & $\begin{array}{l}\text { Study } 102 \\
(n=34)\end{array}$ & $\begin{array}{l}\text { Total } \\
(n=168)\end{array}$ \\
\hline Patients with TEAEs, n (\%) & $11(44.0)$ & $10(43.5)$ & $6(13.6)$ & $11(26.2)$ & $23(67.6)$ & $61(36.3)$ \\
\hline \multicolumn{7}{|l|}{ Total number of TEAEs by severity } \\
\hline Mild & 26 & 11 & 8 & 10 & 40 & 95 \\
\hline $\begin{array}{l}\text { Total number of discontinuations due to } \\
\text { treatment-related AEs }\end{array}$ & 0 & 1 & 0 & 0 & 1 & 2 \\
\hline
\end{tabular}

the vehicle-treated lesion (primary outcome). Five patients $(20.0 \%)$ had a greater decrease in the ADSI score for the vehicle-treated lesion compared with the crisaborole-treated lesion. Statistically significant differences favoring crisaborole treatment were observed at day 14 (secondary outcome), day 28 (primary outcome) and day 42 (secondary outcome) (Figure 4) [83]. Overall, more crisaborole-treated patients experienced early and sustained improvement in lesion-specific disease severity, indicating a promising efficacy profile for crisaborole.

Study 203 was a Phase II multicenter, open-label, 29-day safety study that enrolled patients aged $12-17$ years who had AD involving 10 to $35 \%$ of the treatable BSA [84]. The proportion of patients who achieved various ISGA thresholds throughout the study is summarized in Figure 5 (secondary outcome). At day 29, 8 of 23 patients (34.8\%) achieved treatment success (secondary outcome; ISGA score $\leq 1$ and $\geq 2$-grade improvement from baseline).

Study 204 (NCT01602341) was a Phase II multicenter, randomized, double-blind, bilateral, doseranging study that included patients aged $12-17$ years who had AD involving up to $35 \%$ of total BSA [85]. The study assessed the effects of Crisaborole Topical Ointment, $2 \%$ and $0.5 \%$, administered once daily or twice daily. Mean ADSI scores improved over time during treatment with Crisaborole Topical Ointment, $2 \%$ (primary outcome), with a dose-related effect observed across the four treatment regimens. The greatest improvement from baseline was observed in lesions treated with Crisaborole Topical Ointment, $2 \%$, applied twice daily (Figure 6). Similarly, the proportion of lesions with total or partial clearance (ADSI $\leq 2$; secondary outcome) increased over time in a dose-related manner.

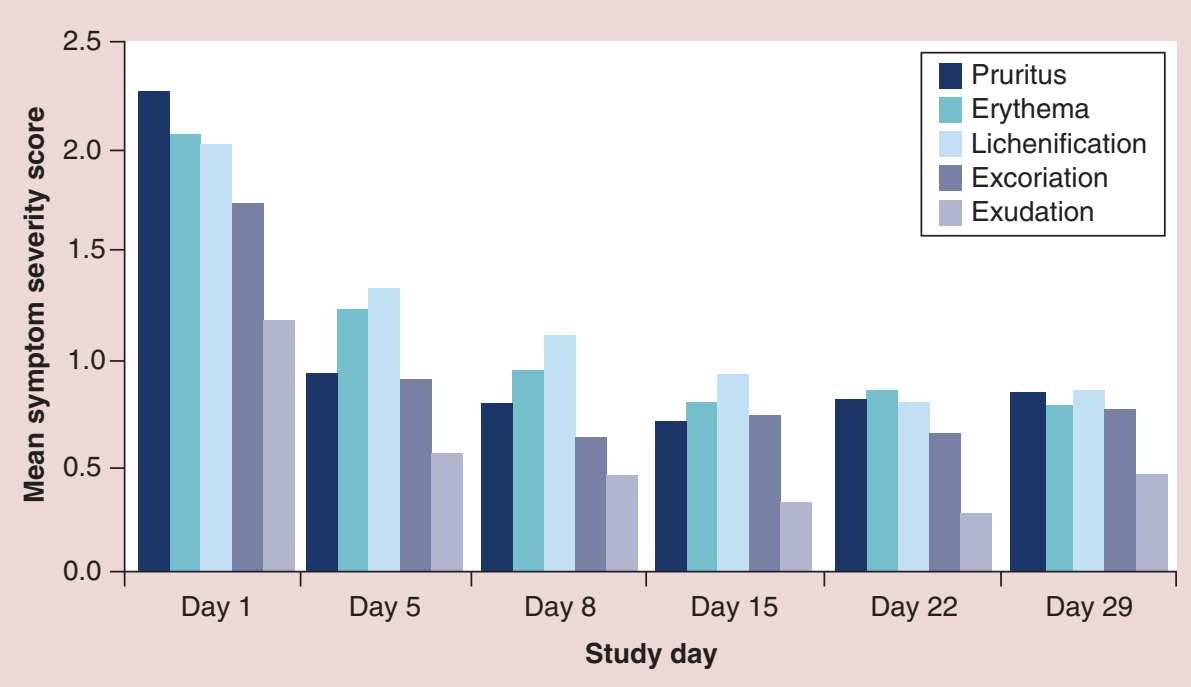

Figure 3. Study 102: Decrease in mean severity scores of signs and symptoms of atopic dermatitis (Atopic Dermatitis Severity Index [ADSI] components) at days 1, 5, 8, 15, 22 and 29. 


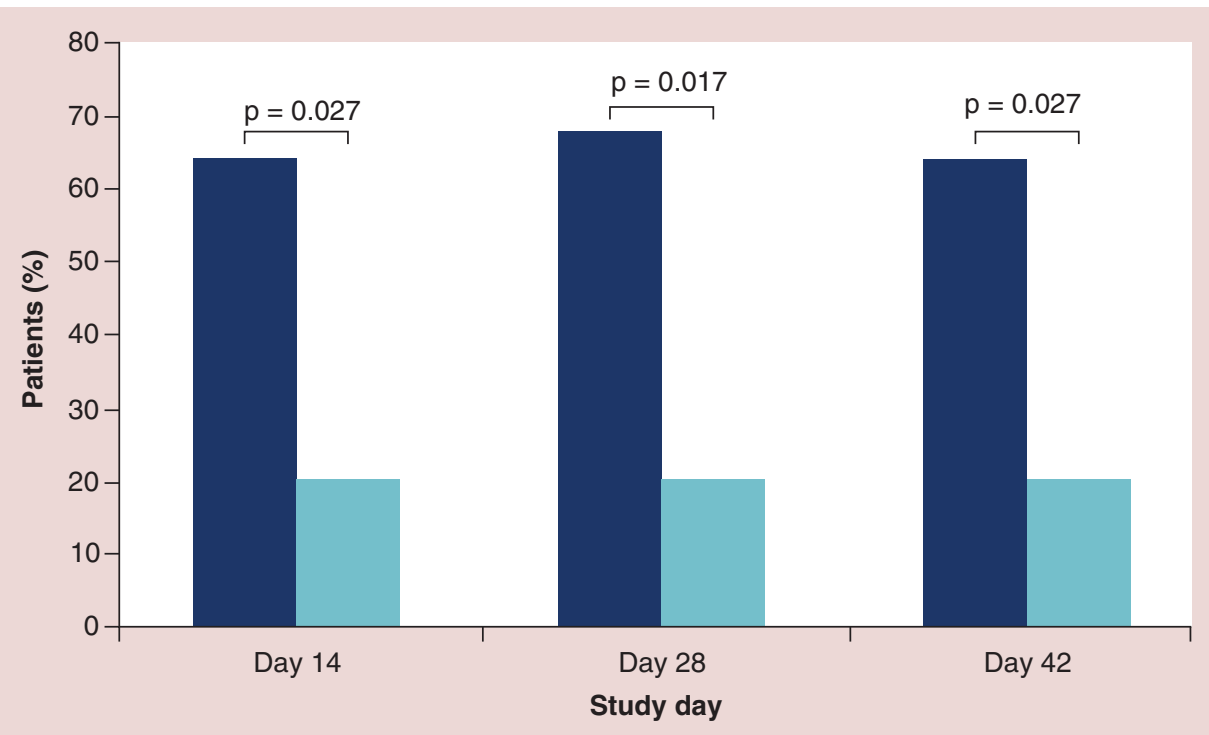

Greater decrease in active-treated lesion

Greater decrease in vehicle-treated lesion

Figure 4. Study 202: Proportion of patients with a greater Atopic Dermatitis Severity Index (ADSI) score decrease from baseline for lesions treated with Crisaborole Topical Ointment, 2\%, versus vehicle at days 14, 28 and 42.

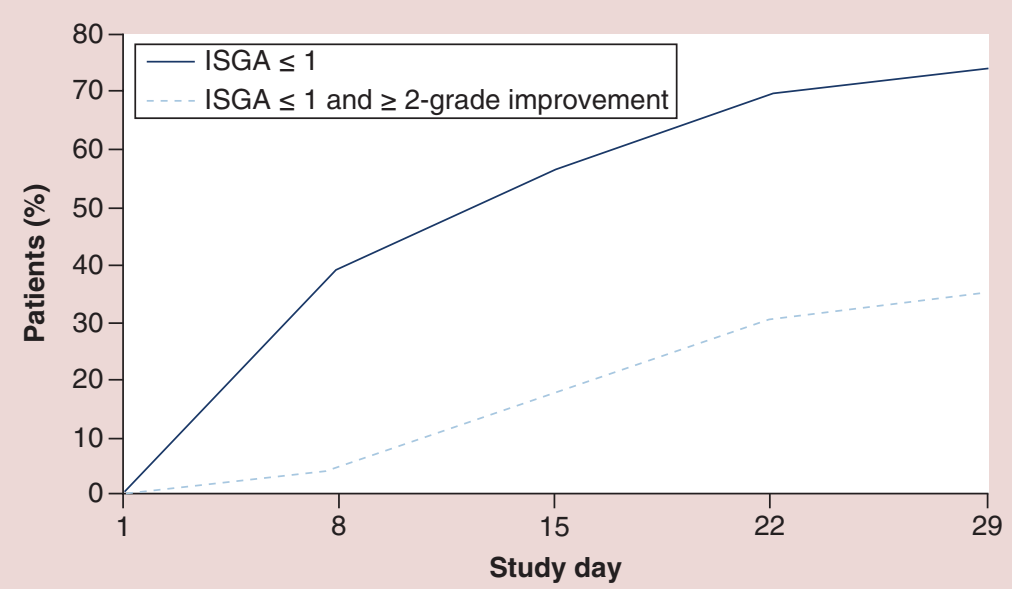

Figure 5. Study 203: Proportion of patients who achieved Investigator's Static Global Assessment (ISGA) thresholds during treatment with Crisaborole Topical Ointment, $2 \%$.

A pooled analysis of Studies 102/203 and 202/204 revealed a significant reduction in the severity of pruritus, which was assessed as a secondary measure using a 4-point scale (0 [none] to 3 [severe]) [87]. The analysis of Studies 102 and 203 (whole-body assessments) revealed that $77.2 \%$ of patients had moderate to severe pruritus at baseline. By day 8 (first assessment) of treatment with Crisaborole Topical Ointment, $2 \%$, this number decreased to $8.8 \%$ (Figure 7A). Similarly, an analysis of Studies 202 and 204 (bilateral target lesion assessments) demonstrated a reduc- tion in the proportion of patients with moderate to severe pruritus from $85.1 \%$ at baseline to $9.5 \%$ by day 8 (Figure 7B). Weekly assessment demonstrated these improvements continued throughout the treatment period.

\section{Future perspective: ongoing development}

Potential areas for future research include analysis in patients 3 months to $<2$ years of age, after a favorable efficacy and safety profile is demonstrated in the older patient population. Two large Phase III clinical trials 


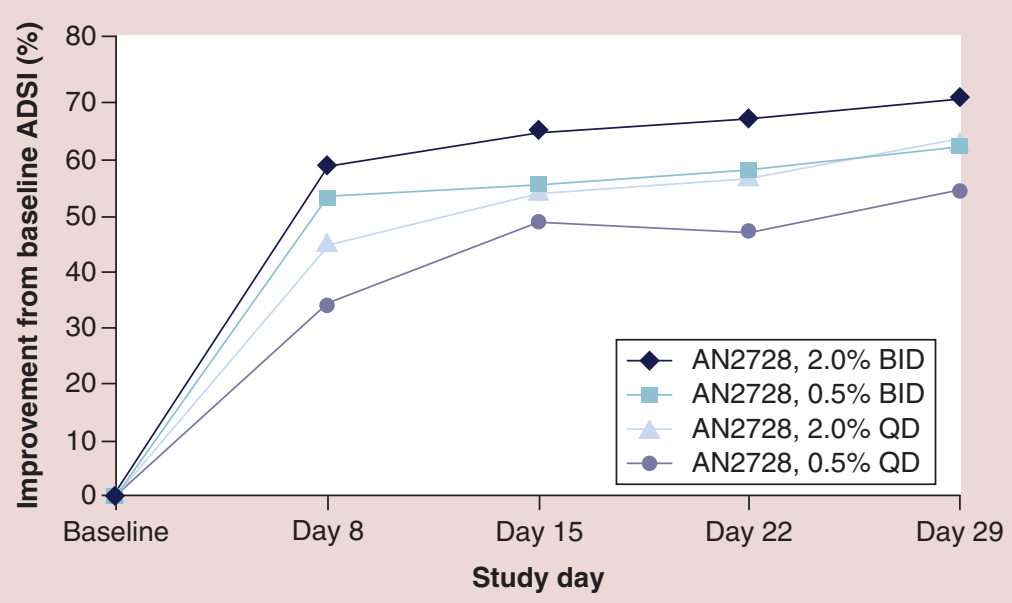

Figure 6. Study 204: Changes from baseline in the ADSI score at days 1, 8, 15, 22 and 29.

ADSI: Atopic Dermatitis Severity Index; BID: twice daily; QD: once daily.

of identical design have been conducted to evaluate the efficacy and safety of Crisaborole Topical Ointment, $2 \%$, in patients as young as 2 years of age with mild to moderate AD (NCT02118766, NCT02118792). Efficacy end points analyzed improvement in global disease severity (primary end point), time to improvement in disease severity, change in severity of signs of $\mathrm{AD}$ (secondary end points) and time to improvement in pruritus (additional efficacy end points). Participants in these Phase III studies were eligible to enter an open-label, long-term safety extension trial. Data are being compiled for the two pivotal Phase III trials and the open-label extension trial, all of which have been completed.

\section{Conclusion}

$\mathrm{AD}$ is a complex chronic inflammatory skin disorder that occurs largely in children and primarily presents as mild to moderate disease [1-4]. The distressing itch and other symptoms of AD impose a significant burden on patients and their parents [5,9-12]. Pruritus-induced scratching can further damage the skin and promote secondary infection, exacerbating symptoms, worsening disease severity and further diminishing patients' QoL [3,16-18].

In patients with $\mathrm{AD}$, skin barrier disruption, combined with immune dysregulation, results in the production of inflammatory cytokines, causing $\mathrm{AD}$ exacerbations and pruritus [12,30]. PDE 4 is overactive in AD skin, resulting in depressed intracellular cAMP levels, which leads to the production of inflammatory cytokines provoking AD exacerbations [12,31,33-36].

Topical therapies for AD have changed very little over the past 15 years, relying heavily on TCS and TCI [66]. These broadly acting therapeutic categories require healthcare providers to weigh the need for symptomatic relief against safety concerns [14]. Furthermore, TCS and TCI have restrictions in terms of appropriate treatment areas and duration of use $[19,20,64,67]$. Given the limitation of these agents, there remains a need for a topical nonsteroidal, antiinflammatory agent that safely minimizes the symptoms and severity of AD and can be used for acute and maintenance therapy.

Boron chemistry enabled the synthesis of crisaborole, a low-molecular-weight, selective, topical PDE4 inhibitor that effectively penetrates the skin [77-79]. Crisaborole acts by inhibiting PDE4 to reduce inflammation in $\mathrm{AD}$ [35,78-80]. Furthermore, the unique topical formulation of crisaborole allows for targeted inhibition at the site of inflammation and rapid metabolism, thus avoiding systemic exposure and potential offtarget side effects such as gastrointestinal side effects (nausea and diarrhea) often associated with oral PDE4 inhibitors [88,89].

Results from four Phase I and Phase II studies show that Crisaborole Topical Ointment, 2\%, appears to be well tolerated, with limited systemic exposure, including under maximal-use conditions. These findings may support favorable safety and tolerability of crisaborole in adults, adolescents, and children as young as 2 years of age, as analyzed in Study 102. Additionally, treatment with crisaborole improved disease severity, pruritus intensity, and all other assessed AD signs and symptoms. These results suggest that crisaborole may target the underlying pathogenesis of disease in patients with $\mathrm{AD}$. The efficacy and safety demonstrated by Crisaborole Topical Ointment, 2\%, an investigational nonsteroidal, topical anti-inflammatory agent, indicates that the drug targets the underlying pathogenesis of $\mathrm{AD}$ to reduce the symptoms and severity of mild to moderate $\mathrm{AD}$. 
(A)

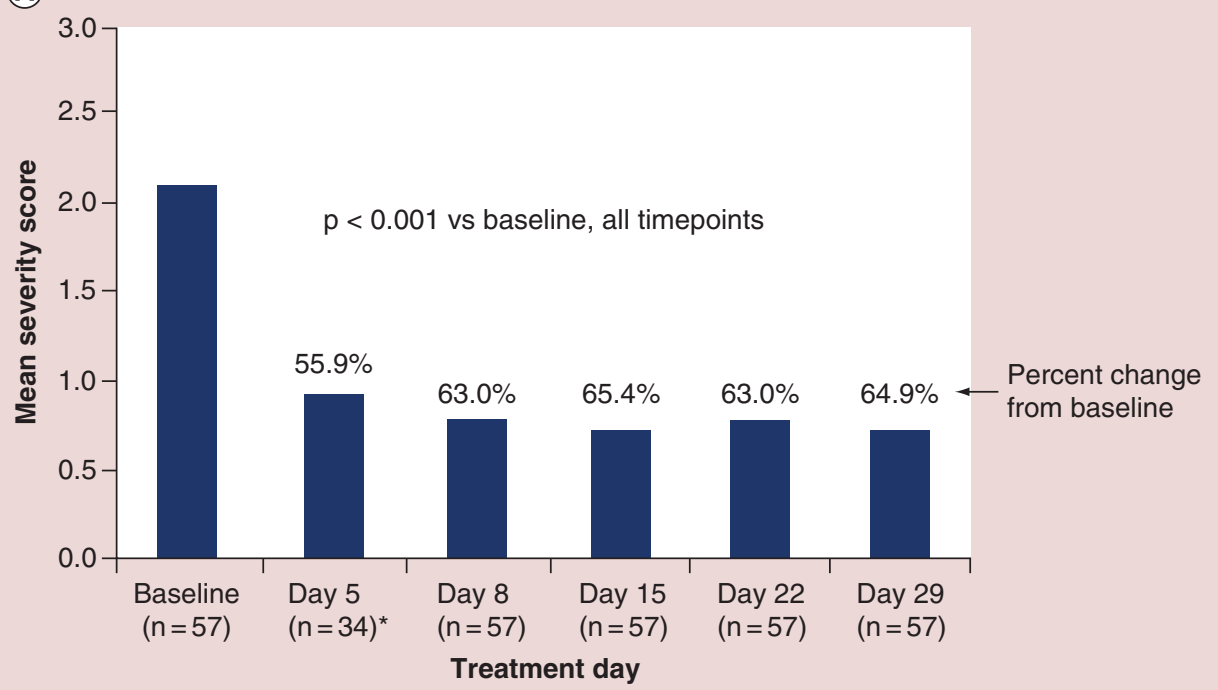

(B)

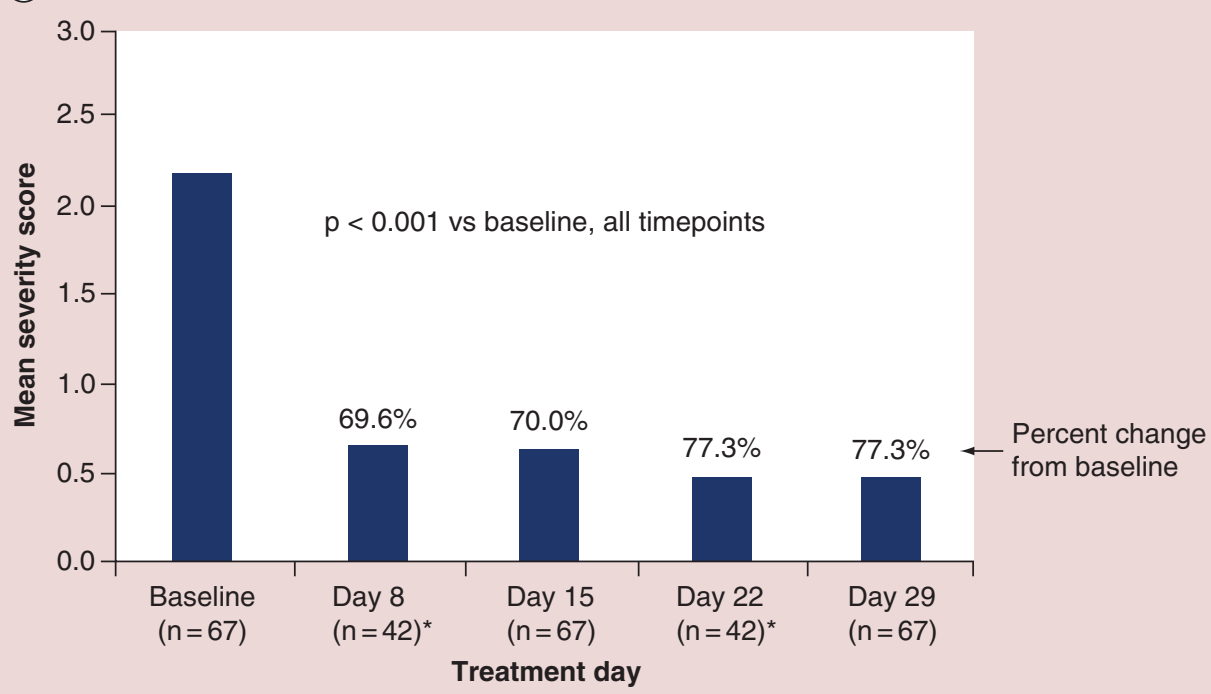

Figure 7. Reduction in pruritus severity scores in children and adolescents treated with Crisaborole Topical Ointment, $2 \%$. These data are from a pooled analysis of whole-body assessments from (A) studies 102 (Phase lb) and 203 (Phase II) and (B) target lesion assessment from studies 202 and 204 (both Phase II)."Day 5 scores were available from study 202 only.

Pruritus severity scale: $0=$ no itching; $1=$ occasional, slight itching; $2=$ constant or intermittent itching with no sleep disturbance; 3 = bothersome itching that disturbs sleep or normal activity.

Financial \& competing interests disclosure

LT Zane, S Chanda, K Jarnagin and DB Nelson are employees and stockholders of Anacor Pharmaceuticals, Inc. L Spelman has served on the advisory Boards for Eli Lilly, Galderma, Novartis and Abbvie. She has undertaken sponsored clinical research for Anacor, Ascend Biopharmaceuticals, Astellas, Australian Wool Innovation Limited, Dermira, Genentech, GlaxoSmithKline and Trius. She has received sponsored travel from Abbott, Novartis and Janssen-Cilag. L Stein Gold has received honorarium as an advisory board participant for Gal- derma, Leo, Valeant, Allergan, Novartis, Lilly, Pfizer, Taro and Anacor, and as a speaker for Galderma, Leo, Valeant, Allergan, Novartis and Taro. The authors have no other relevant affiliations or financial involvement with any organization or entity with a financial interest in or financial conflict with the subject matter or materials discussed in the manuscript apart from those disclosed.

Writing assistance was utilized in the production of this manuscript. Writing assistance was provided by ApotheCom and funded by Anacor Pharmaceuticals, Inc. 


\section{Etiology}

- Atopic dermatitis (AD) is a chronic inflammatory skin disease affecting infants, children and adults.

- Increased levels of phosphodiesterase 4 (PDE4) activity and subsequent increases in inflammation are seen in patients with active AD.

Burden of atopic dermatitis

- One of the major criteria for AD diagnosis, pruritus, is a key contributor to the reduced quality of life observed in patients with $A D$.

- Breaking the itch-scratch cycle is essential to improve disease control, prevent chronicity and scarring and improve patient quality of life.

\section{Current topical treatment paradigms for atopic dermatitis}

- Current pharmacologic treatments for atopic dermatitis have not changed over the past 15 years and consist of topical corticosteroids (TCS) and topical calcineurin inhibitors (TCI).

- TCS and TCl are associated with use restrictions and safety concerns, therefore a targeted, safe and effective treatment is much needed.

Development of Crisaborole Topical Ointment, $2 \%$, for atopic dermatitis

- Crisaborole is a small-molecule, boron-based, nonsteroidal anti-inflammatory PDE4 inhibitor.

- The physicochemical properties and low molecular weight of crisaborole make it suitable for topical formulation and allow it to penetrate the epidermis and dermis to reach the site of inflammation.

- Phase I and II clinical trials have been completed for Crisaborole Topical Ointment, 2\%, as a monotherapy for the treatment of mild to moderate AD.

- Pharmacokinetic studies have demonstrated that crisaborole is rapidly absorbed and quickly metabolized to two identified inactive metabolites, reducing the risk of systemic exposure and unwanted systemic side effects.

- Across all four Phase I and II studies, the majority of treatment-emergent adverse events were mild to moderate, demonstrating a favorable safety profile for crisaborole.

- Crisaborole-treated patients demonstrated significant improvements in disease severity, as well as a significant reduction in pruritus.

\section{Conclusion}

- Crisaborole is a first-in class, nonsteroidal, topical anti-inflammatory, PDE inhibitor for the treatment of mild to moderate AD.

- Studies performed indicate a favorable efficacy and safety profile for crisaborole in children and adults with mild to moderate AD.

- Significant improvement in disease severity, pruritus intensity, and all other assessed signs and symptoms of $A D$ indicate that crisaborole may target the underlying pathogenesis of the disease.

\section{References}

Papers of special note have been highlighted as: $\bullet$ of interest; $\bullet \bullet$ of considerable interest

1 Bieber T. Atopic dermatitis. N. Engl. J. Med. 358(14), 1483-1494 (2008).

2 Bieber T. Atopic dermatitis. Ann. Dermatol. 22(2), 125-137 (2010).

3 Yosipovitch G, Papoiu AD. What causes itch in atopic dermatitis? Curr. Allergy Asthma Rep. 8(4), 306-311 (2008).

4 Eichenfield LF, Tom WL, Berger TG et al. Guidelines of care for the management of atopic dermatitis. section 2. Management and treatment of atopic dermatitis with topical therapies. J. Am. Acad. Dermatol. 71(1), 116-132 (2014).

$5 \quad$ Nutten S. Atopic dermatitis. global epidemiology and risk factors. Ann. Nutr. Metab. 66(Suppl. 1), 8-16 (2015).

6 Thomsen SF. Atopic dermatitis. natural history, diagnosis, and treatment. ISRN Allergy 2014, 354250 (2014).

7 Akdis CA, Akdis M, Bieber T et al. Diagnosis and treatment of atopic dermatitis in children and adults. European
Academy of Allergology and Clinical Immunology/American Academy of Allergy, Asthma and Immunology/PRACTALL Consensus Report. J. Allergy Clin. Immunol. 118(1), 152-169 (2006).

8 Margolis JS, Abuabara K, Bilker W, Hoffstad O, Margolis DJ. Persistence of mild to moderate atopic dermatitis. JAMA Dermatol. 150(6), 593-600 (2014).

9 Blume-Peytavi U, Metz M. Atopic dermatitis in children. Management of pruritus. J. Eur. Acad. Dermatol. Venereol. 26(Suppl. 6), 2-8 (2012).

10 Brown MM, Chamlin SL, Smidt AC. Quality of life in pediatric dermatology. Dermatol. Clin. 31(2), 211-221 (2013).

11 Weidinger S, Novak N. Atopic dermatitis. Lancet 387(10023), 1109-1122 (2015).

12 Hanifin JM, Chan SC, Cheng JB et al. Type 4 phosphodiesterase inhibitors have clinical and in vitro antiinflammatory effects in atopic dermatitis. J. Invest. Dermatol. 107(1), 51-56 (1996).

- Discusses the increased activity of cyclic AMP and PDE4 
in patients with $\mathrm{AD}$. In vitro analysis demonstrates targeting PDE4 reduces the production of proinflammatory cytokines.

13 Fowler JF, Duh MS, Rovba L et al. The direct and indirect cost burden of atopic dermatitis. An employer-payer perspective. Manag. Care Interface 20(10), 26-32 (2007).

14 Carr WW. Topical calcineurin inhibitors for atopic dermatitis. Review and treatment recommendations. Paediatr. Drugs 15(4), 303-310 (2013).

15 Romeo SP. Atopic dermatitis. The itch that rashes. Pediatr. Nurs. 21(2), 157-163 (1995).

16 Hong J, Buddenkotte J, Berger TG, Steinhoff M. Management of itch in atopic dermatitis. Semin. Cutan. Med. Surg. 30 (2), 71-86 (2011).

17 Segal AO, Ellis AK, Kim HL. CSACI position statement. safety of topical calcineurin inhibitors in the management of atopic dermatitis in children and adults. Allergy Asthma Clin. Immunol. 9(1), 24 (2013).

18 De Benedetto A, Agnihothri R, McGirt LY, Bankova LG, Beck LA. Atopic dermatitis. A disease caused by innate immune defects? J. Invest. Dermatol. 129(1), 14-30 (2009).

19 Arkwright PD, Motala C, Subramanian H, Spergel J, Schneider LC, Wollenberg A. Management of difficult-totreat atopic dermatitis. J. Allergy Clin. Immunol. Pract. 1(2), 142-151 (2013).

20 Charman C, Williams $\mathrm{H}$. The use of corticosteroids and corticosteroid phobia in atopic dermatitis. Clin. Dermatol. 21(3), 193-200 (2003).

21 Weber M, Mazzotti N, Petry V, Cestari T, Weis L. Evaluating the relation between pruritus, serum IgE levels and severity of clinical manifestations in atopic dermatitis patients. An. Bras. Dermatol. 80 (3), 245-248 (2015).

22 Eyerich K, Novak N. Immunology of atopic eczema. Overcoming the Th1/Th2 paradigm. Allergy 68(8), 974-982 (2013).

23 Barnes KC. An update on the genetics of atopic dermatitis. Scratching the surface in 2009. J. Allergy Clin. Immunol. 125(1), 16-29 (2010).

24 Boguniewicz M, Leung DY. Atopic dermatitis. A disease of altered skin barrier and immune dysregulation. Immunol. Rev. 242(1), 233-246 (2011).

25 Leung DY. New insights into atopic dermatitis. Role of skin barrier and immune dysregulation. Allergol. Int. 62(2), 151-161 (2013).

26 Guttman-Yassky E, Nograles KE, Krueger JG. Contrasting pathogenesis of atopic dermatitis and psoriasis-part I. Clinical and pathologic concepts. J. Allergy Clin. Immunol. 127(5), 1110-1118 (2011).

27 Bunikowski R, Mielke M, Skarabis $\mathrm{H}$ et al. Prevalence and role of serum IgE antibodies to the Staphylococcus aureusderived superantigens SEA and SEB in children with atopic dermatitis. J. Allergy Clin. Immunol. 103(1 Pt 1), 119-124 (1999).

28 Salt BH, Boguniewicz M, Leung DY. Severe refractory atopic dermatitis in adults is highly atopic. J. Allergy Clin. Immunol. 119(2), 508-509 (2007).
29 Gupta J, Grube E, Ericksen MB et al. Intrinsically defective skin barrier function in children with atopic dermatitis correlates with disease severity. J. Allergy Clin. Immunol. 121(3), 725-730 (2008).

30 Grewe SR, Chan SC, Hanifin JM. Elevated leukocyte cyclic AMP-phosphodiesterase in atopic disease. A possible mechanism for cyclic AMP-agonist hyporesponsiveness. J. Allergy Clin. Immunol. 70 (6), 452-457 (1982).

31 Baumer W, Hoppmann J, Rundfeldt C, Kietzmann M. Highly selective phosphodiesterase 4 inhibitors for the treatment of allergic skin diseases and psoriasis. Inflamm. Allergy Drug Targets 6(1), 17-26 (2007).

32 Novak N, Bieber T, Leung DY. Immune mechanisms leading to atopic dermatitis. J. Allergy Clin. Immunol. 112(Suppl. 6), S128-S139 (2003).

33 Essayan DM, Huang SK, Kagey-Sobotka A, Lichtenstein LM. Differential efficacy of lymphocyte- and monocyteselective pretreatment with a type 4 phosphodiesterase inhibitor on antigen-driven proliferation and cytokine gene expression. J. Allergy Clin. Immunol. 99(1 Pt 1), 28-37 (1997).

34 Essayan DM, Huang SK, Undem BJ, Kagey-Sobotka A, Lichtenstein LM. Modulation of antigen- and mitogeninduced proliferative responses of peripheral blood mononuclear cells by nonselective and isozyme selective cyclic nucleotide phosphodiesterase inhibitors. J. Immunol. 153(8), 3408-3416 (1994).

35 Dastidar SG, Rajagopal D, Ray A. Therapeutic benefit of PDE4 inhibitors in inflammatory diseases. Curr. Opin. Investig. Drugs 8(5), 364-372 (2007).

36 Jimenez JL, Punzon C, Navarro J, Munoz-Fernandez MA, Fresno M. Phosphodiesterase 4 inhibitors prevent cytokine secretion by $\mathrm{T}$ lymphocytes by inhibiting nuclear factor-kappaB and nuclear factor of activated T cells activation. J. Pharmacol. Exp. Ther. 299 (2), 753-759 (2001).

37 Torphy TJ. Phosphodiesterase isozymes. Molecular targets for novel antiasthma agents. Am. J. Respir. Crit. Care Med. 157(2), 351-370 (1998).

38 Giembycz MA. Phosphodiesterase 4 and tolerance to beta 2-adrenoceptor agonists in asthma. Trends Pharmacol. Sci. 17(9), 331-336 (1996).

39 Gonzalez GA, Montminy MR. Cyclic AMP stimulates somatostatin gene transcription by phosphorylation of CREB at serine 133. Cell 59(4), 675-680 (1989).

40 Wen AY, Sakamoto KM, Miller LS. The role of the transcription factor CREB in immune function. J. Immunol. 185(11), 6413-6419 (2010).

41 Hou S, Guan H, Ricciardi RP. Phosphorylation of serine 337 of NF-kappaB p50 is critical for DNA binding. J. Biol. Chem. 278(46), 45994-45998 (2003).

42 Kwak HJ, Song JS, Heo JY, Yang SD, Nam JY, Cheon HG. Roflumilast inhibits lipopolysaccharide-induced inflammatory mediators via suppression of nuclear factorkappaB, p38 mitogen-activated protein kinase, and c-Jun NH2-terminal kinase activation. J. Pharmacol. Exp. Ther. 315(3), 1188-1195 (2005). 
43 Chow CW, Davis RJ. Integration of calcium and cyclic AMP signaling pathways by 14-3-3. Mol. Cell. Biol. 20(2), 702-712 (2000). Stork PJ, Dillon TJ. Multiple roles of Rap1 in hematopoietic cells. Complementary versus antagonistic functions. Blood 106(9), 2952-2961 (2005). regulation-overview of mechanisms of action in T cells. Cell. Signal. 23(6), 1009-1016 (2011).

Williams HC, Burney PG, Hay RJ et al. The U.K. Working Party’s Diagnostic Criteria for Atopic Dermatitis. I. Derivation of a minimum set of discriminators for atopic dermatitis. Br. J. Dermatol. 131(3), 383-396 (1994).

47 Williams HC, Burney PG, Pembroke AC, Hay RJ. The U.K. Working Party's Diagnostic Criteria for Atopic Dermatitis. III. Independent hospital validation. Br. J. Dermatol. 131(3), 406-416 (1994).

48 Hachisuka J, Takeuchi S, Kido M, Fukiwake N, Furue M. Severity of disease, rather than xerosis, correlates with pruritus in patients with atopic dermatitis. Int. J. Dermatol. 48(4), 374-378 (2009).

49 National Collaborating Centre for Women's and Children's Health (2007). www.ncc-wch.org.uk/

50 Sheehan-Dare RA, Henderson MJ, Cotterill JA. Anxiety and depression in patients with chronic urticaria and generalized pruritus. Br. J. Dermatol. 123(6), 769-774 (1990).

51 Halvorsen JA, Lien L, Dalgard F, Bjertness E, Stern RS. Suicidal ideation, mental health problems, and social function in adolescents with eczema. A population-based study. J. Invest. Dermatol. 134(7), 1847-1854 (2014).

52 Carroll CL, Balkrishnan R, Feldman SR, Fleischer AB Jr, Manuel JC. The burden of atopic dermatitis. Impact on the patient, family, and society. Pediatr. Dermatol. 22(3), 192-199 (2005).

53 Schut C, Bosbach S, Gieler U, Kupfer J. Personality traits, depression and itch in patients with atopic dermatitis in an experimental setting. A regression analysis. Acta Derm. Venereol. 94(1), 20-25 (2014).

54 Dieris-Hirche J, Gieler U, Kupfer JP, Milch WE. [Suicidal ideation, anxiety and depression in adult patients with atopic dermatitis]. Hautarzt 60(8), 641-646 (2009).

55 Simpson EL. Comorbidity in atopic dermatitis. Curr. Dermatol. Rep. 1(1), 29-38 (2012).

56 Kimata H. Prevalence of suicidal ideation in patients with atopic dermatitis. Suicide Life Threat. Behav. 36(1), 120-124 (2006).

57 Dalgard FJ, Gieler U, Tomas-Aragones L et al. The psychological burden of skin diseases. a cross-sectional multicenter study among dermatological out-patients in 13 European countries. J. Invest. Dermatol. 135(4), 984-991 (2015).

58 Noh HM, Cho JJ, Park YS, Kim JH. The relationship between suicidal behaviors and atopic dermatitis in Korean adolescents. J. Health Psychol. pii: 1359105315572453(2015) (Epub ahead of print).

59 Mina S, Jabeen M, Singh S, Verma R. Gender differences in depression and anxiety among atopic dermatitis patients.
Indian J. Dermatol. 60(2), 211 (2015).

60 Picardi A, Lega I, Tarolla E. Suicide risk in skin disorders. Clin. Dermatol. 31(1), 47-56 (2013).

61 Lewis-Jones S. Quality of life and childhood atopic dermatitis. The misery of living with childhood eczema. Int. J. Clin. Pract. 60(8), 984-992 (2006).

62 Garcia PL, Ebert U. Frontiers of rapid itch relief. A review of methylprednisolone aceponate. J. Eur. Acad. Dermatol. Venereol. 26(Suppl. 6), 9-13 (2012).

63 Spergel JM, Paller AS. Atopic dermatitis and the atopic march. J. Allergy Clin. Immunol. 112(Suppl. 6), S118-S127 (2003).

64 Schneider L, Tilles S, Lio P et al. Atopic dermatitis. A practice parameter update 2012. J Allergy Clin. Immunol. 131(2), 295-299 (2013).

65 Lio PA. Non-pharmacologic therapies for atopic dermatitis. Curr. Allergy Asthma Rep. 13(5), 528-538 (2013).

66 Callen J, Chamlin S, Eichenfield LF et al. A systematic review of the safety of topical therapies for atopic dermatitis. Br. J. Dermatol. 156(2), 203-221 (2007).

67 Rathi SK, D’Souza P. Rational and ethical use of topical corticosteroids based on safety and efficacy. Indian J. Dermatol. 57(4), 251-259 (2012).

68 Arellano FM, Wentworth CE, Arana A, Fernandez C, Paul CF. Risk of lymphoma following exposure to calcineurin inhibitors and topical steroids in patients with atopic dermatitis. J. Invest. Dermatol. 127(4), 808-816 (2007).

69 Nnuroka EN, Daramola OOM, Ike SO. Misuse and abuse of topical steroids. Implications. Expert Rev. Dermatol. 2(1), 31-40 (2007).

70 Kragballe K. Topical corticosteroids. Mechanisms of action. Acta Derm. Venereol. 151, 7-10 (1989).

71 Akers WA. Risks of unoccluded topical steroids in clinical trials. Arch. Dermatol. 116(7), 786-788 (1980).

72 Hajar T, Leshem YA, Hanifin JM et al. A systematic review of topical corticosteroid withdrawal ("steroid addiction") in patients with atopic dermatitis and other dermatoses. J. Am. Acad. Dermatol. 72(3), 541-549 (2015).

73 Smith SD, Hong E, Fearns S, Blaszczynski A, Fischer G. Corticosteroid phobia and other confounders in the treatment of childhood atopic dermatitis explored using parent focus groups. Australas. J. Dermatol. 51(3), 168-174 (2010).

74 Arellano FM, Arana A, Wentworth CE, FernandezVidaurre C, Schlienger RG, Conde E. Lymphoma among patients with atopic dermatitis and/or treated with topical immunosuppressants in the United Kingdom. J. Allergy Clin. Immunol. 123(5), 1111-1116 (2009).

75 Margolis DJ, Abuabara K, Hoffstad OJ, Wan J, Raimondo D, Bilker WB. Association between malignancy and topical use of pimecrolimus. JAMA Dermatol. 151(6), 594-599 (2015).

76 Luger T, Boguniewicz M, Carr W et al. Pimecrolimus in atopic dermatitis. Consensus on safety and the need to allow use in infants. Pediatr. Allergy Immunol. 26(4), 306-315 (2015). 
77 Compound Summary for CID 44591583. PubChem Open Chemistry Database 906673-24-3 (2015). https://pubchem. ncbi.nlm.nih.gov/compound/906673-24-3

78 Akama T, Baker SJ, Zhang YK et al. Discovery and structure-activity study of a novel benzoxaborole antiinflammatory agent (AN2728) for the potential topical treatment of psoriasis and atopic dermatitis. Bioorg. Med. Chem. Lett. 19(8), 2129-2132 (2009).

79 Nazarian R, Weinberg JM. AN-2728, a PDE4 inhibitor for the potential topical treatment of psoriasis and atopic dermatitis. Curr. Opin. Investig. Drugs 10(11), 1236-1242 (2009).

- Discusses the promising therapeutic potential for crisaborole demonstrated in preclinical and Phase I and II trials for crisaborole for patients with psoriasis and atopic dermatitis.

80 Freund YR, Akama T, Alley MR et al. Boron-based phosphodiesterase inhibitors show novel binding of boron to PDE4 bimetal center. FEBS Lett. 586(19), 3410-3414 (2012).

81 Jarnagin K, Chanda S, Coronado D et al Crisaborole topical ointment, $2 \%$. a nonsteroidal, topical, anti-inflammatory phosphodiesterase 4 inhibitor in clinical development for the treatment of atopic dermatitis. J. Drugs Dermatol. 15(4), 390-396 (2016)

-. Discusses the physical properties and preclinical development of crisaborole.

82 Zane LT, Kircik L, Call R et al. AN2728 Topical ointment, $2 \%$ in patients 2 to 17 years of age with atopic dermatitis. A phase $1 \mathrm{~b}$, open-label, maximal-use systemic exposure (MUSE) study. Pediatr. Dermatol. (2016). (In Press)

-• Discusses the Phase $1 \mathrm{~b}$ analysis of the pharmacokinetics, safety and efficacy of crisaborole topical ointment in patients ages 2-17 with $\mathrm{AD}$.

83 Murrell D, Gebauer K, Spelman L, Zane LT. Crisaborole topical ointment, $2 \%$ in adults with atopic dermatitis. A Phase 2A, vehicle-controlled, proof-of-concept study. J. Drugs Dermatol. 14(10), 19-23 (2015).
- Discusses the Phase II efficacy and safety analysis of Crisaborole Topical Ointment, $2 \%$ in patients ages $12-17$ with mild-to-moderate $\mathrm{AD}$.

84 Tom WL, Van SM, Chanda S, Zane LT. Pharmacokinetic profile, safety, and tolerability of crisaborole topical ointment, $2 \%$ in adolescents with atopic dermatitis. An open-label Phase 2a study. Pediatr. Dermatol. 33(2), 150-159 (2016).

- Discusses the Phase IIa pharmacokinetic, safety and efficacy analysis of Crisaborole Topical Ointment, 2\%.

85 Stein Gold LF, Spelman L, Spellman MC, Hughes MH, Zane LT. A phase 2, randomized, controlled, dose-ranging study evaluating crisaborole topical ointment, $0.5 \%$ and $2 \%$ in adolescents with mild to moderate atopic dermatitis. J. Drugs Dermatol. 14(12), 1394-1399 (2015).

- Discusses the Phase II efficacy and safety analysis of Crisaborole Topical Ointment, $2 \%$ in patients ages $12-17$ with mild-to-moderate AD.

86 Liu L, Musick TJ, Luo G et al. In vitro and in vivo investigation on metabolic fate of AN2728, a novel boron based small molecules for treatment of psoriasis and atopic dermatitis. Presented at: 18th North American Regional ISSX. Dallas, TX, USA, 14-18 October 2012.

87 Draelos ZD, Stein Gold LF, Murrell DF, Hughes MH, Zane LT. Post hoc analyses of the effect of crisaborole topical ointment, $2 \%$ on atopic dermatitis. associated pruritus from Phase 1 and 2 clinical studies. J. Drugs Dermatol. 15(2), 172-176 (2016).

-• Discusses the post-hoc analysis from Phase I and II studies demonstrating crisaborole ointment significantly reduces pruritus severity in patients with $\mathrm{AD}$.

88 Moustafa F, Feldman SR. A review of phosphodiesteraseinhibition and the potential role for phosphodiesterase 4-inhibitors in clinical dermatology. Dermatol. Online J. 20(5), 22608 (2014).

89 Wittmann M, Helliwell PS. Phosphodiesterase 4 inhibition in the treatment of psoriasis, psoriatic arthritis and other chronic inflammatory diseases. Dermatol. Ther. (Heidelb.) 3(1), 1-15 (2013). 